\title{
Quantification, Rationality, And Management Decisions
}

John Mankelwicz, Troy University - Southeast Region, USA

Robert Kitahara, Troy University - Southeast Region, USA

\begin{abstract}
Quantitative approaches have long dominated the management literature and influenced practice. But why?? The emphasis on quantification constitutes part of intended rationality. Yet it is not mathematical elegance or logical rigor that ultimately shapes the course of decision and final outcomes, but rather the experience of quantification and the use of the numbers. Building on classical sources from Aristotle to Herbert Simon, and Diesing's five rationality types, this essay positions quantification as one determinant of performance, within an overall model framework employing rationality as an intervening variable.
\end{abstract}

Keywords: Rationality, management decisions, quantitative methods

\section{INTRODUCTION}

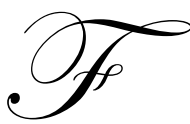

ormal mathematical tools, computer techniques, and quantitative metrics are a mainstay for many management decisions. Managers seem to grow increasingly dependent upon these aids, which are made central from their early training. The resultant solutions, justified by "the numbers," allow analysis of complex business problems. Managers may simultaneously attack problems with a goulash of informal, intuitive, emotional, or political processes. This trend has been long term. An intense interest in measurement attended the introduction of the "American system" of interchangeable machine parts in the late nineteenth century. This system spread rapidly due to immense size of US markets, the shortage of labor craftwork, and the rise of transportation networks, particularly railroads (Derry \& Williams, 1960; Chandler, 1977).

Executive excesses, such as those at Enron, have drawn media attention. Reacting to these events, many now question the utility of formal, quantitative procedures and the efficacy of the resulting numerical outputs for guiding business and investment decision. Despite the abuses, new theories and procedures for quantitative analysis abound, as do systems for integrating them with less formal methods (Cascio, 2007). Modern organization, technology, and managerial practice demand quantitative methods and large volumes of data. Quantification itself impacts the course of decision-making, as psychological processes from the individual level reinforce institutional level impacts.

But why do "the numbers" matter? And matter so much? The authors suggest that it is an aspect of intended rationality (Simon, 1945): managers seek to enhance rationality, to improve decision quality, through the use of quantitative methods and their outputs. Indeed, an emphasis on quantification is a distinguishing feature of modern conceptions of rationality, as opposed to ancient, classical, primarily Aristotelian conceptions (Nozick, 1993). The paper posits a simple, positive, and monotonic relationship, expressed as Figure 1. Yet this simple, almost trite answer masks many other questions, among them: What is a degree of quantification? Rationality in what sense(s)? What kinds of performance are relevant? Do attempts to enhance rationality always result in better performance? 


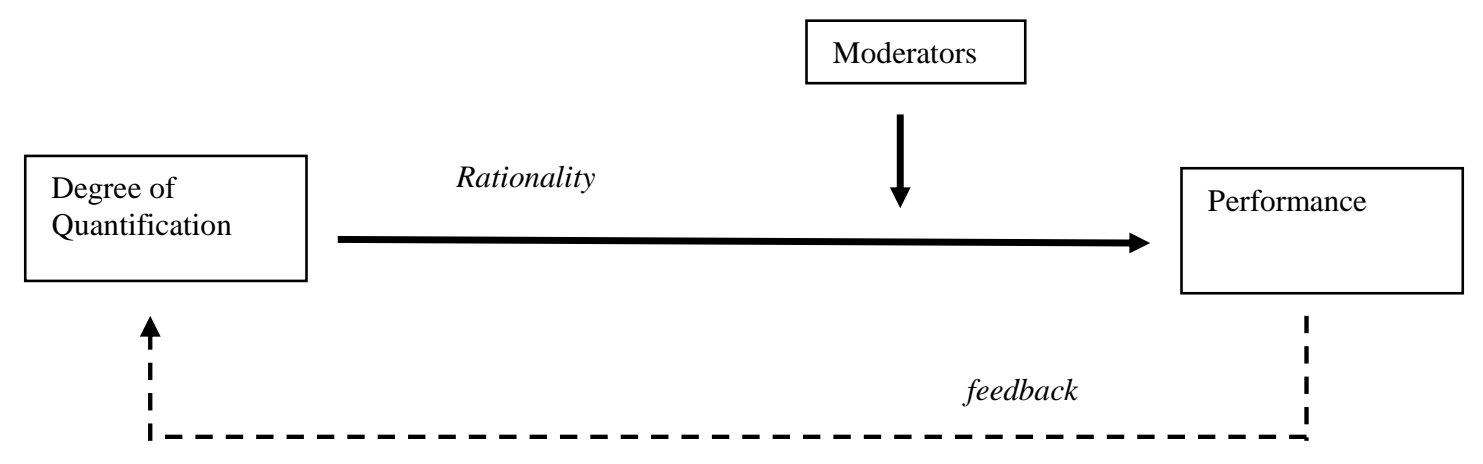

Figure 1: Greater quantification increases rationality and ultimately performance.

Again, "the numbers" really do matter! Briefly, the argument runs as follows. Numbers play important roles in the processes of contemporary management decision-making. Managers rely on established theories and practices of their functions: finance, marketing, operations etc. The disciplines underlying these functional areas have accepted paradigms, or at least "exemplars" (Kuhn, 1980) that suggest, even prescribe, which sets of concepts, variables, and methods are proper for use in analyses. Thus paradigms and theory inform decision processes throughout an organization. Indeed, the very nature of paradigms treats problems as solvable "puzzles." Managers will demand and use numbers because they believe their functional roles (and the underlying paradigms) call for them.

However, it is not the mere presence of sophisticated paradigms, quantitative methodologies and massive databases that enhances rational decision-making. It is the manner in which managers utilize these devices that is critical. To utilize them, managers must experience them. Hence, it is not mathematical elegance or logical rigor that ultimately shapes the course of decision and final outcomes, but rather the manager's experience of quantification and the use of the numbers. Their responses under this experience leads to both intended and unanticipated consequences. For the purposes at hand, any attempt to define a level of quantification must therefore consider this personal experience, over and even above the more formal aspects. The boundedness of rationality has great implications for quantification in management, affecting the way managers experience numbers and quantity.

Beyond reliance on the knowledge base of their functional areas, there is little evidence that managers explicitly map specific elements of quantification to aspects of rationality. Rather, they seem to consider rationality as an assumed intervening variable, linking various factors to performance. A given variable may be independent, dependent, intervening, etc. - depending on the context of study. Hence, for purposes of exposition, Figure 1 renders rationality as an intervening variable.

Though intervening variables are not themselves directly measured, the choice of a particular intervening variable as a linking mechanism has great implications. In this context, the choice of rationality provides a convenient framework for considering the difficult task of dealing with the kinds of performance. Presumably each kind of performance might respond to quantification differently. Problems are the ordinary trigger for managerial decision, and problems differ substantively, as they deal with technical, economic, social, legal, or political issues; each of these kinds of issue demands a different type of rationality (Diesing, 1962) and performance. While the loci of problem types may vary across organizational levels, an executive deals at some time with all of them. Further, performance is not a dead end; performance provides feedback, and each kind of performance might also behave differently as a feedback mechanism, both at the organizational and individual levels, perhaps especially so at the latter (Ilgen, et. al., 1979). Finally, the usual suspects appear here as candidate moderator variables: individual differences, group characteristics, task and characteristics, organizational structure and culture, among others. Intuitively, each kind of rationality/issue type would also have distinctively salient moderators.

The discussion will first give a very short history of general conceptions of rationality and then quantification. It then examines how managers experience numbers. Employing the rationality framework of 
Diesing (1962), it will suggest how the degree of quantification impacts rationality in the five classes of problems and associated decisions.

\section{RATIONALITY}

The nature of rationality has concerned both writers and decision makers since ancient times. It has been described in terms of calculation, application of rules, or creativity. Aristotle regarded rational thought, along with basic sociability, as defining attributes of mankind (Hartman, 2006). The term has referred to both the processes by which choices result (procedural rationality) and often to the choices themselves (substantive rationality). Herbert Simon $(1945,1983)$ set the tone for modern discussions of rationality; he emphasized quantitative methods as part of managers' efforts to be "intendedly rational." Yet at most anyone achieves only a "bounded rationality." Reviewing difficulties with this concept, he concludes "a decision may be called 'objectively' rational if in fact it is the correct behavior for maximizing given values in a given situation. It is 'subjectively' rational if it maximizes attainment relative to the actual knowledge of the subject" (Simon, 1945, p. 76). In his view, most initial attention may be profitably directed not toward the final decision but to clarity and verify the premises of the decision. Similarly, Kepner \& Tregoe (1965) stress attention to exact specification of magnitude, location, and time of variables as the key to problem formulation, the foundation of effective managerial decision-making.

Following Simon (1945, 1995), rationality describes patterns of action toward given goals (utility functions, values), although limited by given constraints. When some of these constraints are within the cognitive capacity of the focal actor, there is bounded rationality. The boundedness arises from risk, uncertainty, or complexity in the basic functions (demand, cost) involved in managerial choice. It may also come from incomplete information concerning alternatives or consequences, or from cognitive and computational inadequacies that impede determination of the structure of the overall decision environment. Intended but bounded rationality may be conceived in various ways. As Simon (1986) points out, "almost all the action will lie in these auxiliary assumptions about attention and belief that define the decisionmakers's frame." Increases in the Degree of Quantification (DOQ) of Figure 1 are seen as increasing rationality by relaxing the bounds upon it.

How does this play out in the context of management practice? Asked to define rationality, most practitioners would likely mention "facts and common sense." While they would probably not take issue with the emphasis on goals and consistent choice, they would say that choice should be sensible and fact based. Common sense is not necessarily common; nevertheless, a sensible approach for this inquiry would favor seeming common sense over theory, welcome the available empirical evidence, and focus especially on variables and phenomena directly available to managers: the agreed upon, available facts.

Management is of course concerned with the classic functions of planning, leading, organizing, and controlling. To theses ends organizations routinely gather much numerical data, with greater volume for major or novel decisions. Serious analysis occurs in response to "problemistic search" (Simon, 1945), as a manager or trusted staffer perceives some problem or opportunity (Segev, 1977) and "triggers" the decision making process. The process deals with problems of choice and allocation, with problems considered as "gaps" between a desired state of affairs (a goal, value) and an actual state of affairs (Kepner and Tregoe, 1965). Managers are wise to search even while scarce data constitute only a "weak signal," when only the source and general nature of event(s) are known (Ansoff, 1975). They systematically develop the picture until the impacts, courses of response, and final outcomes are known. Considerable mindfulness may be necessary to avoid truncation of search or distorted decision processes (Kozielecki, 1972; Mankelwicz \& Kitahara, 2008) due to overemphasis on the earliest quantitative data obtained. Managers, staff, and their statements appear most rational and credible when citing early quantitative data, using familiar variables from a paradigm accepted by management.

\section{QUANTIFICATION}

As with rationality, scholars have long concerned themselves with quantification. A variety of number systems and calculating apparatuses date to the earliest civilizations: Egypt, Babylon, China, and India. Very basic and commercially relevant units (such as length, weight, volume, and time) varied greatly by society and era (Derry $\&$ Williams, 1960). As in the modern world, trade and governmental uses followed on the heels of achievements of 
proto-scientists, or "natural philosophers." However, the scientific measurements and counts attempted by these early peoples were subject to continual error from gravity, earth's orbital motion, latitude, and instrumental error, among many factors. "It is a myth that the ancients were accurate observers." (Gillispie, 1960, p. 17) In ancient Greece, the Pythagoreans were perhaps the first to be obsessed with numbers, which they believed to be the basic units of reality, typically taking simple geometric shape; numbers were both ideal and real, providing the form and deep structure of reality beneath surface appearance. Although fading into a mythic past, the Pythagoreans greatly influenced the later Classical world.

While rejecting many of their ideas, Aristotle considered quantity to be one of the most critical categoria of human thought and discourse; indeed most of Aristotle's attentions seem directed at only four of his ten categories: substance, quality, quantity, and relation. In quantity, "magnitude" reflected the idea of the continuity of metric characteristics, while "multitude" indicated the discontinuity of a meristic or countable characteristic. In Aristotelian logic, quantification meant the application of universal or particular quantifiers (all, no, some) to terms of a categorical proposition, which appears to unite these quantifiers with categories (usually substance or quality). This is analogous to the modern practice of recognizing established "dimensions" for numerical measurements; hence, most physical quantities are one-dimensional scalars, but may be vectors, tensors, or some other multidimensional quantity. In management practice, monetization of quantities plays a similar role.

Aristotle's work has remained an underpinning of Western thought to this day. However, to both him and Plato, there was a divorce of mathematics from physics and chemistry (Gillispie, 1960), since so many qualities seemed unamenable to mathematical treatment. This rift did not begin to close until Galileo began the modern scientific tradition. First, he revised traditional views of time, explicitly introducing it into precise mathematical formulations for motion, velocity, and acceleration. Galileo also "distinguished between primary and secondary qualities in bodies. The primary he defined as properties essential to metrical description - length, width, height, figure. The secondary - color, taste, odor, and texture - are those which are modes of perception in us, rather than real essences permeating matter. The difference is that between object and subject." (Gillispie, 1960, p. 41) Thus he affected a partial remarriage of physics and mathematics; physics remains the science in which measurement is most developed. At the same time Galileo intellectually separated ethics and its adherent issues as secondary qualities, poorly amenable to scientific measurement; in this he foreshadowed Hume. Meanwhile, chemistry "had become a science, but a qualitative rather than metrical one. An analogous stage occurs with more or less importance in the evolution of every science, during which it explains effects as real qualities occurring out in nature." (Gillispie, 1960, p. 205) However, it was not until much later that "in practise as in principle, Newton achieved the correct relationship between physics as the science of metrics and mathematics as the language of quantity." (Gillispie, 1960, p. 144) The path to maturity in chemistry was also long and circuitous (Kuhn, 1980).

Modern practices retain much of ancient thought, but in extended and improved ways. Logic emphasizes universal or existential quantifiers. In mathematical or scientific discussion, the term quantification indicates measuring or counting. Perhaps the most prominent management use of quantification is measurement, the mapping of observations onto a set of numbers. Strictly speaking, we do not measure things, or qualities, or properties, but "indicants" of properties. Measurement combines the categories of quality and quantity: to establish the quantity of a particular quality. "The qualities in things are what impress our senses, our windows on reality, and this reality inheres, not in mass, but in the principles which run through the world as activities, as bearers of quality and agents of perceived effects." (Gillispie, 1960, p. 185) Again, in measurement a number is not usually used by itself, but in tandem with some other term, its dimension, which still today will normally correspond to some Aristotelian category of substance or quality.

Actually, dimension of a quantity is not a single concept, since it is possible to dimensionalize a given set of numbers in many ways. Indeed, mathematicians love to dimensionalize, seeking to achieve the goals Einstein set out to achieve in his 40 year search for a "theory of everything." Although there is no full scientific consensus, many believe that the expansion of quantum field theory of modern physics into String Theory or Superstring Theory (Zwiebach, 2009) may yet provide a unifying explanation for all forces and matter. Based on multi-dimensional constructs, this framework allows at least 10 dimensions. 
Practicing managers, however, must experience relevant numbers as phenomena - through their senses. Human perception may be as bounded in scope as our rationality. Keeping us grounded, Stephen Hawking (1988) invokes the Anthropic Principle of physics to explain why we are able to perceive only three spatial dimensions and one time dimension. Were there fewer than this, our physiology could not function. (Or at least we could not perceive it to do so.) Were there more dimensions, our physical laws, such as gravity, would break down (or seem to do so). While mathematics and modern physics has soared, the human faculties leave the practitioner at classical physics, which "ended as it had begun in Galileo's law of falling bodies - with a redefinition of the physical meaning of time." (Gillispie, 1960, p. 518)

Many regard quantity itself as a quality, and this has become a mantra for many qualitative management researchers. Thus to quantify is to add the quality of quantity to a set of one or more qualities. Kenneth Boulding asserts, "...there is no essential difference, therefore, between a quantity, which we think to measure exactly, and a quality. A quantity merely has a larger number of grades," (Boulding, 1962, p. 3). At first there are only the simplest logical operators, such as "all" or "no." True quantification must be above the nominal level of measurement, to at least the ordinal level, so that the quality in question may have ordered "grades," in whatever units these are expressed. Establishment of ordered grades immediately allows logical quantifiers to be used for comparison, such as "more than," or "less than."

Management has aspects of both art and applied science. Artistic, intuitive choice of the right substantive qualities for consideration is often a key skill of successful of managers. Also, following the pattern of the sciences generally, careful attention to quantification helps the manager to avoid basing decisions on inappropriate data sets. There are many threats effective quantification. Conversion to monetary units distorts some data. The upward flow of aggregated numbers renders information less timely or specific, facilitating mistakes while making fraud less visible.

For rationality, the data available must at a minimum allow quantitative comparison of values, so that choices may be made to maximize the appropriate value or metric. Variables at the ordinal or even at the nominal level of measurement can be useful for this purpose, as is frequently instantiated in qualitative research. Thus an interval or ratio level of measurement is neither necessary nor sufficient for rational choice. The level at which a variable may be measured - nominal, ordinal, interval, or ratio - is indeed an important element in the degree of quantification. It should not, however, be used as a surrogate approximation for this overall degree. All of the functions of management research - description, classification, prediction, explanation, control - can in principle be fulfilled at least basically by use of the appropriate variables at any level of measurement. While more sophisticated analyses may require higher levels of measurement, correct choice of variables and knowledge of relationships have even greater importance for management practice.

\section{EXPERIENCING QUANTIFICATION}

It is critical to consider the way that managers actually perceive and experience "the numbers." There would be myriad ways in which to describe manager's experience of quantification. At the most abstract level, numbers and quantification belong to Aristotle's category called quantity; thus one might seek description in terms of logic in the conjunction of categories of substance, quality, and relation. Possibly a description could draw upon contributions concerning other complex and elusive phenomena, such as time. Certainly many important variables, such as money and information, have critical time values. There is also a vast psychological and philosophical literature on time (Ornstein, 1969; Morgenstern, 1960). Among still other approaches, one might relate quantification to the descriptive parameters of production technologies, or perhaps those job-related technologies that managers themselves use. The approach here will focus on managers' perceptions and cognitions, their actions, and the symbolic-emotive response to quantities. The factors of time and logical relation become entwined in the causal attribution necessary for much of analysis. Key variables, decision-making language, and logical apparatuses from the favored paradigms of managers' formal training inform a structure for organizing these elements.

In the complexity of the real world, the set of optimal choices is not given, but must be found. It requires search and analysis of considerable amounts of data. Organizations collect numerical data largely to measure and compare performances: of individuals, groups, or the organization as a whole. The most important mechanisms 
relate to reception of performance feedback, managerial attributions, and cognitive simplifications. Although executives rarely invoke the formal language of causation, much decision analysis is causal in nature. For explanation, higher degrees of quantification can allow more rigorous attributions of event and fact causation (Mackie, 1974), and only these allow decisions that reliably yield intended consequences.

However, executives rarely ruminate on the universal and existential quantifiers of logic, nor dwell on such concepts as the Level of Quantification (LOQ), the lowest level at which a chemical substance can be accurately measured.

The time value of money is taken for granted. Educed from managerial parlance, managers' experience of numbers and quantity is quite commonplace rather than ethereal. The experience is much like that of the average citizen, only magnified due to the sheer volume of data submitted by and to management.

Managers are people, and "people value the creation of certainty over an equally valued shift in the level of uncertainty. Interestingly, the perception of certainty (that is, the perception that the probability of an event is zero or 1.0) can be easily manipulated." (Bazerman \& Moore, 2009, p 68) For example, through selective presentation of information, advertisers and others are able to create a false sense of overall certainty, or "pseudo-certainty," by suggesting certainty about some subset of relevant uncertainties.

However, only facts are truly certain. "We observe objects, processes, and events. But facts must be a different kind of denotatum, logically different.... Facts are what true statements state." (Hanson, 1971, p. 9-10) There is thus an a posteriori nature to facts. Statements of the future may be excellent conjectures, may be true to an actor's intentions, and may turn out to be true, but they cannot be taken as statements of fact. "But if the past is the domain of knowable facts over which I have no power, it is also the domain of knowable fact...we always consider that they are in principle verifiable." (de Jouvenel, 1967, p 4). Quantitative models provide output numbers that represent theoretical equilibria, optima, or desired states. Past accuracies in relevant analyses form part of the basis for senior managers' present trust in their key staff; in turn staffers (along with the managers themselves) practice "uncertainty absorption' (March \& Simon, 1958) for the organization.

For many purposes, and especially for explanation, the manager is concerned with facts. Where there is little historical data or where things are changing rapidly, a "regularity," or event causation set of attributions may not be possible. Fact causation is in any event superior for explanation (Mackie, 1974). Facts are "those objective organizations of the objects, events, and states of affairs within a scientific subject matter which render true the theories we do hold." (Hanson, 1971, p, 12) There is an intricate relationship between paradigm and fact. Paradigms not only prescribe choice of methods and variables, but they allow us to recognize facts. Accordingly, facts "are just those conditions a subject matter meets such that a given theory might be applied to it - the boundary conditions. In that sense the facts are 'theoretically determined.' (Hanson, 1971, p9-10)

Not just numerals, but numbers themselves may become symbols. Symbols can be very powerful - that is, exposure to and experience of symbols may result in significant effect on mood, attitude, and behavior. The appearance of a symbol may sensitize, and facilitate recognition of facts. Numbers may accurately represent an actual state of affairs, or at least the best conception or projection of one. When the relevant numbers are probabilities, individuals tend to round upward high probabilities to create "certainties," and to round downward very low probabilities to zero, or non-occurrence (Kahnemann \& Tversky, 1979).

Numbers may also convey moral symbolism. Appearance of some key number may allow a person to perceive evidence of a moral problem gap - a deviation of actual conduct from that desired under an ethical code, formal or not.. He then passes through stages of If this problem has high "moral intensity" (Jones, 1991), the person will be more likely to perceive it and also to continue through Rest's (1986) stages of moral judgment, intention to act, and finally action. Jones' model defines six dimensions of moral intensity: magnitude of effect, probability of effect, concentration of effect (on a target group), social consensus about the conduct and impacts, immediacy in time, and proximity in space. Each dimension is readily quantifiable. The moral intensity concept remains prominent as one of the few reliable linkages between quantification and ethics. Two of the dimensions - the magnitude of effect and a general social consensus - are especially potent to build moral awareness even in highly competitive environments, as long as specific ethically charged terms are employed (Butterfield, et. al., 2006). 


\section{QUANTIFICATION AND RATIONALITY}

Diesing's (1962) framework is that of a generalist concerned with effectiveness - the production of some kind of value. Each of his five types of rationality characterizes a sphere of order and effectiveness. These spheres hold and produce elements, which are selected and perpetuated by a characteristic selective process. Diesing emphasizes that reason has historically been considered as creativity, application of rules, or as calculation. These rationalities rely on different social sciences, follow different trends of development, employ causal inference differently, or may primarily concern specific managerial levels and specialists. The dimensions of quantities will also differ among the types of rationality because of the paradigms these rationalities may invoke and the variables these paradigms will consider. The overall pattern of rationality is an intertwining of the paradigms and interdisciplinary matrices (Kuhn, 1980) of the underlying sciences. To Diesing, rationality is, because of these interrelations, "a creature of the order it creates." Technical and economic orders especially stress efficiency, but overall rationality is ultimately about the broader concept of effectiveness. The discussion will treat quantification in each rationality type, in relation to managerial level and function and the selective dynamics of the type.

\section{Technical Rationality}

In many ways this is the clearest, crispest, simplest type of rationality, and it basically deals with the efficient accomplishment of single goals (Diesing, 1962), most often those pertaining to the physical production or transport of a good or service. In the comparatively closed technical production environment (Thompson, 1967), efficiency measures can prevail. Techniques of measurement here are most rigorous, the physical sciences are invoked, and much data is taken on many variables. It is definitely rationality as calculation, under some constraint by rules. Hence, this is the type of rationality in which quantification is most obvious, and within each production unit there will be numerous indices and criteria to measure production, efficiency, and performance. Variables are typically measured at the interval or ratio level. This is the level at which subjective rationality and objective rationality will be closest. It is also here where there is the most explicit concern with time. Quantitative rigor weds to strong social construction of organizational reality (Berger \& Luckmann, 1967).

Technical managers deal with many physical qualities and quantities. The units used to measure or express a quantity depend on the dimension of the quantity. All physical quantities, however, derive from the seven dimensionally independent quantities of length, mass, time, electric current, temperature, amount of a substance, and luminous intensity. At the same time, there is a great emphasis on monetization. In an established enterprise, technology is most particularly the concern of unit managers, who may practice the technology by themselves, or they may delegate the tasks with relative ease to technical staff. Accountants and monitors both assist and harass the technical manager.

In the technical environment both "fact" and "event" causation (Mackie, 1974) are appropriate. Technical procedures, scientific paradigms, and manual and textbook training (Kuhn, 1980) may be so broadly accepted that fact causation is easily invoked, since the paradigms will clearly recognize certain facts as adequate explanations. When operations are running well, but schedules are also tight, managers can seem more interested in simple descriptive monitoring and next round prediction; voluminous data collection allows them to rely on Humean regularity of technical events (event causation), which presumably reflect what the technical paradigms would recognize as facts. The emphasis is on seeking simple regularities, as Poincare so eloquently expressed. "Trying to make science contain nature is like trying to make the part contain the whole. But scientists believe that there is a hierarchy of facts, and that a judicious selection can be made...The most interesting facts are those which can be used several times, which have a chance of recurring... we must prefer facts which appear simple, to those in which our rude vision detects dissimilar elements." (Poincare, 1908, 2004, p. 4-5).

Most elements in the productive environment are controlled or controllable; many of these elements would be moderating variables in the schema of Figure 1, and rational managers would seek to set levels of these variables optimally for goal attainment. Accordingly, one might ironically conjecture that, in the absence of external disturbances, the possible remaining increases in Degree of Quantification (DOQ) would have little impact on Technical Rationality. The conjectured level for the DOQ may be succinctly described by the implicit function

$\mathrm{DOQ}=\mathrm{f}$ (number of variables, level of measurement, number of observations) 


\section{Economic Rationality}

This type of rationality also deals with efficient goal achievement, but of multiple goals (Diesing, 1962) with choice among goals. It too is calculation, but with even greater rule constraint. The paradigms underlying analysis usually derive from neoclassical economics and accounting, which pursue substantive rationality with a focus on choices, not the processes by which they are made (Simon, 1986). Accordingly, causal attribution centers, internal to the firm, on technical and cost issues - matters of fact. Externally the dynamic is driven by market demand, and possibly also by regulation. The interaction of these factors yields a set of possible market prices, or a single market price under perfect competition. This fact - the emergence of a price - dominates further market action. Hence fact causality is the dominant form of attribution. There remains some small space for Aristotle's "efficient" cause by individuals, a special case of fact causation. This is due mainly to irrational matters such as miscalculation, personal pique, etc.

The goods and services produced under economic rationality are morally neutral, measurable, divisible, ordinarily monetizable, etc. Organizations employ very familiar numerical, typically monetized metrics: stock price, accounting profit, ROA, risk adjusted measures, quick ratio, market share, etc. Managers and external stakeholders accept the financial and accounting metrics as clear performance feedback for the company. Economics is silent concerning goal or value content, and assumes globally consistent rational behavior toward both current and future decision environments. The involvement of top and middle management is very evident in economic rationality (Simon, 1947), and there will thus also be a pattern of sequential shift of managerial attention from issue to issue (Allison, 1971).

The conjectured level for the DOQ is taken from economic theory, as adequately identified and constrained equations - demand, supply, revenue, cost, and profit - along with sufficient data to employ them.

\section{Social Rationality}

Social rationality is the form, which makes any action possible; it deals with the integration of elements at any level of society. It is a rationality of creativity rather than calculation. At the lowest level, components of action, components of feeling, or conceptual components - such as beliefs, obligations, expectations, or ideals - are integrated into roles for an individual. Each learned role colors and conditions the next role learned. The sum of these roles over time constitutes personality. Thus the "production" of social rationality is human personality, especially in relation to integration into society. Diesing emphasizes that "often social relations and social action are thought of as irrational or nonrational, in contrast with economic action... One reason for the lack of understanding of social rationality is that it is almost entirely unconscious in its working...traditional theories of practical reason could not deal adequately with unconscious rationality." (Diesing, 1962, p. 65) Accordingly, this is the form of rationality where quantification is least obvious. Paradoxically, and for the very reasons above, this seems to be the type of rationality with which all managers are somehow involved, regardless of their functional area.

Psychology, social psychology, sociology, etc. - instead of economics - are the informing social sciences. While "in economics, rationality is viewed in terms of the choices it produces; in the other social sciences, it is viewed in terms of the processes it employs." (Simon, 1986, p. 210) The difficulties of understanding largely unconscious processes greatly diminish the effective use of "the numbers" in social rationality.

Commensurate with its unconscious operation, social rationality is the weakest type in which to make causal attributions. Very, very rarely is there sufficient volume of data to assemble a "regularity" construction of an "event" cause. However, causal attributions may over time become subconsciously structured into the beliefs, values, and assumptions of the organization's culture. Careful rational thought and an emphasis on quantification may themselves become organizational values. Conscious causal attributions by the social participants in organizations are often clumsy, but Attribution Theory from cognitive psychology (Heider, 1944; Jones \& Davis, 1965; Kelley, 1967) describes the process. Professional analysts, if they attempt attribution at all, are prone toward fact causalities, organized around the assumptions and observations ordinarily recognized as "fact" by the paradigms from the discipline(s) of their training. In social rationality, the relevant substances of events (and facts) should stem from the cognitive and physical actions of individuals. They are thus matters of efficient or "producing" cause. 
Diesing underscores this point: "Presumably causal efficacy can be attributed only to individuals in roles, and not to patterns of any sort." (Diesing, 1962, p. 243) Yet it might prove fruitful to employ other Aristotelian aetia, or conceptions of cause as explanation, that do involve pattern. Formal causation, due to the constraints of existing organization and social structures, is an intuitive candidate. Material causation - from the human material of organizations - sometimes provides as good an explanation as any other. When other avenues fail, social scientists may gain some insight from teleological explanation, invoking final causes, seen as the self-replicating patterns of social structures.

The selective processes create a fundamental trend toward greater integration. However, this progression may be slowed or disrupted by exogenous shocks to a social system, by conflict, or even by equilibrium. Managers must be particularly attentive to those quantitative measures that have reliably indicated social discontent. Tardiness, lateness, and turnover are among these.

\section{Legal Rationality}

This form of rationality deals with the formation and application of rules to guide people in the face of the myriad conflicts that arise from expectations, obligations, and the consequence actions. The trend toward greater integration should in principle steadily diminish conflict, but that end never appears. Indeed, social integration does enable the calculation and activity that produces technology and economic benefit. Nevertheless, for most persons "technological and economic progress attracts attention because of their constructive or destructive effect on social relations, rather than for the increased utility they provide." (Diesing, 1962, p. 75) Destruction of social relations brings conflict, and there must be clear rules, definitive procedures, and impartial adjudication. This adjudication is accomplished by a few rather than a many. For long run effectives, this few must always at least appear very impartial. They also typically have special training and roles: judge, arbitrator, mediator, etc.

There is no absolute distinction between the essential and peripheral norms of society. Presumably each society will code only the most essential into rules, ordinances, or laws. Individual organizations will apparently do the same in their bylaws and policy manuals. In this form of rationality impartial judgment is critical, whether final adjudication is by a formal judge, appointed master, arbitrator, or selected mediator.

An impartial process of adjudication is based upon evidence, interpreted under rules. Evidence is the available facts and the logical inferences that necessarily flow from them. The exactness of data in numerical form gives them credibility; "the numbers" become central to the recognition of something as fact. However, the acceptance of particulars as evidence will vary by jurisdictions, as each may respect differing bodies of legislative and case law, principles of jurisprudence, and professional practices as germane - as the actual, applicable "paradigm" of law.

Conceptions of causality began in early law courts, not in ancient attempts at science. The purpose was logic for determining blame and penalty or innocence and possible reward. Thus in legal rationality also the dominant explanatory mode was the Aristotelian conception of personal efficient cause.

Quantification under legal rationality is only a little easier than in social rationality. Though modern corporations abound in legal talent, it is by no means clear that this always serves the ends of managerial rationality. Specific decisions may involve political matters, discussed below. Also, conflicts may be framed in moral terms, with appeal to patterns established under social rationality. Jones (1991) Issue Contingent Model is useful here. The overall moral intensity of an issue suggests whether it will require eventual adjudication, and the dimensions of effect magnitude and consensus are especially important (Butterfield, et. al., 2006). Jones also emphasized that many organizational factors - authority, group standards, etc. - may act to facilitate or impede moral intentions ever becoming behavior, regardless of the moral intensity value of an issue. In this context the behaviors would be moral protests, or pleas by individuals to the adjudicators; these individuals need not be aggrieved or injured parties. Jones' model thus suggests a variety of interesting organization level moderating variables for consideration. There are also moderators at the personal level. Individual differences also interact with measured moral intensity dimensions (Trevino, et. al. 2006) of an issue to partially explain individual responses. In related research, Reynolds (2006) found that in specific situations, ethical "Utilitarians" become aware of fewer moral issues than "Formalists." 


\section{Political Rationality}

A political decision "is concerned with the preservation and improvement of decision structures...as their special subject matter. Political decisions are ordinarily made by the central authority of a decision structure." (Diesing, 1962, p. 198) This authority must maintain neutrality as it guides the decision structure in accommodating the basic political processes - problem solving, persuasion, bargaining, and politicking. Rather than choice of a clearly best proposed alternative, "compromise is almost always a rational procedure, even when the compromise is between a good and a bad proposal." (Diesing, 1962, p. 204)

Lengthy paths toward compromise - marked by deferral, delay, and copious discussion - will serve to assuage conflict and opposition. If there is an initial lack of value integration in the organization, an aspect of social rationality, it may be impossible for top management to attain sufficient authority and power to resist pressures against its impartiality. However, it might still be able to increase value congruence through educational, ceremonial, or symbolic activities. In leading parties toward compromise, managers may be able to enhance their perceived impartiality by appealing to the rules (legal rationality) as guidance. Personal, efficient causation also dominates political rationality. "Presumably causal efficacy can be attributed only to individuals in roles, and not to patterns of any sort.” (Diesing, 1962, p. 243)

In any referenced social system, political rationality will have a primarily internal focus. An organization's top managers are the usual bearers of central authority, and it is their duty to identify all relevant stakeholders, internal as well as external. Managers must acknowledge their legitimacy, and rank them by salience (Mitchell, et. al., 1997). Each type of stakeholder has its preferred goals and indices of goal attainment: salary, dividends, vacations, etc. The central authority must satisfy each stakeholder at least minimally and provide much more to the most salient stakeholders. This requires significant executive attention. However, rational exercise of authority would also at the same time seek to distribute power more evenly, so that there will optimally be two competing sources of opposition within the organization (Diesing, 1962). More than two truly powerful conflicting camps could result in social fragmentation. However, special attention to the needs and suggestions of the weakest, smallest, and marginal subgroups and individuals is important for overall cohesion; granting more than the minimum demands of these elements may have a powerful symbolic effect yet prove inexpensive quantitatively.

For the above reasons the use of quantitative measures will be different for politically rational decision making; it is probably more difficult. Many relevant quantities may also be counting rather than measured variables. Since it is the decision structure itself that is of concern, identification of both stakeholders' needs and saliences is critical. Both change rapidly, with attendant shifts in the specific relevant metrics and quantities. Quantitative commitments to stakeholders cannot exceed the budget limits. At the same time the total amount of largess may be greater than the more apparent monetary budget, since some actors may accept symbolic payments and promises to remain in the organizational (March, 1962). Even the number and duration of executive appearances can be very symbolic.

Considerations of power become very tricky. The decision structure is partly determined in the composition of the organizational coalition. Ordinarily political rationality suggests slow, careful, nonthreatening change. However, when there is need for major adjustment of the decision structure, the coalition also may require rebuilding. While some stakeholders (particularly externals and marginal internals) will be satisfied with small or symbolic side payments or promises of policy commitments, others will politick actively and then bargain aggressively. The situation becomes analogous to that of voting. Since a voting block's power to affect a result depends on whether its withdrawal would reduce the coalition strength below an effective level, a particular block's power is measurable by use of the Penrose-Banzhaf or Shapley-Shubik Indices (Gelman \& Katz, 2002). Determinations of these index values are conceptually simple but employ computationally tedious formulae. Some conceptual complications do arise, however, since new issues may involve different coalition elements, and each "vote" may occur over time in staged episodes, with persuasion and bargaining in between. The last individual or subgroup to enter the coalition is decisive and has particular bargaining clout. To avoid such complication and uncertainty, political rationality suggests constant vigilance and use of early compromise to avoid such voting impasses in the first place. 


\section{CONCLUSION}

The premise of this paper has been that "the numbers" do indeed matter in decision-making and that managers utilize quantitative methods and data to be rational. Management literature, as well as commonplace experience, suggests that it is the manner in which executives experience the numerical data, rather than mathematical elegance, that shapes decision. Of course, there are different meanings to rationality, and the relevant experience and use of this data will be different under each. Diesing's (1962) framework of five rationality types continues to provide a useful framework for analysis. Managerial experience is clear, although sometimes deceptively simple, under technical and economic rationality, the types of greatest concern to lower and middle management. Social rationality involves all management levels, but its processes are largely invisible, so that intervention based on quantitative evidence may be less effective or foregone altogether. Legal rationality explicitly utilizes numerical inputs, as much to maintain apparent impartiality as the content of decisions. Political rationality, by upper ranks, employs such data to effetely compromise and create viable coalitions in the decision-making structure.

\section{REFERENCES}

1. Allison, G. T. (1971) Essence of decision: Explaining the Cuban missile crisis. Boston: Little, Brown.

2. Ansoff, H. I. (1975) Managing Strategic Surprise by Response to Weak Signals. California Management Review, 18(2):21-23.

3. Bazerman, M. H. \& Moore, D. A. (2009) Judgment in managerial decision making. Hoboken, NJ: John Wiley .

4. Berger, P. L. \& Luckmann, T. (1967) The social construction of reality: A treatise on the sociology of knowledge. Garden city, NY: Anchor

5. Boulding, K. E. (1962) Conflict and defense: A general theory. New York; Harper \& Row.

6. Butterfield, K. D., Trevino, L. K. \& Weaver, G. R. (2006) Moral Awareness in Business Organizations: Influences of Issue-related and Social Context Factors. Human Relations, 53: 981-1018.

7. Cascio, W. F. (2007) Evidence-Based Management and the Marketplace for Ideas. Academy of Management Journal, 50:1009-1012.

8. Chandler, A. D. (1977) The visible hand. Cambridge, MA: Harvard University Press.

9. de Jouvenel, B. (1967) The art of conjecture. London: Basic Books.

10. Derry, T. K. \& Williams, T. I. (1960) A short history of technology. Oxford: Oxford University Press.

11. Diesing, P. (1962) Reason in society: Five types of decisions and their social conditions. Chicago: University of Illinois Press.

12. Gelman, A. \& Katz, J. (2002), The Mathematics and Statistics of Voting Power. Statistical Science 17 (4): 420-435

13. Gillispie, C. C. (1960) The edge of objectivity: An essay in the history of scientific ideas. Princeton, NJ:Princeton University Press.

14. Hanson, N. R. (1971) Observation and explanation: A guide to the philosophy of science. New York: Harper \& Row.

15. Hartman, E. M. (2006) Can We Teach Character? An Aristotelian Answer. Academy of Management Learning and Education. 5(1) 68-81.

16. Hawking, S. (1988) A brief history of time. New York: Bantam books.

17. Heider, F. (1944) Social Perception and Phenomenal Causality. Psychological Review, 51: 358-374.

18. Ilgen, D. R., Fisher, C.D. \& Taylor, M. S. (1979) Consequences of Individual Feedback on Behavior in Organizations. Journal of Applied Psychology, 64(4):349-371

19. Jones, E. E. \& Davis, K. E. (1965) From Acts to Dispositions: The Attribution Process in Person Perception. In L. Berkowitz (ed.) Advances in experimental social psychology, vol. 2, New York: Academic Press.

20. Jones, T. M. (1991) Ethical Decision making by Individuals in Organizations: An issue- contingent model. Academy of Management Review, 16:366-395

21. Kahnemann, D. \& Tversky, A. (1979) Prospect Theory: An Analysis of Decisions Under Risk. Econometrica, 47: 263-291. 
22. Kelley, H. H. (1967) Attribution Theory in Social Psychology, in D. Levine (ed.), Nebraska Symposium on Motivation, 15: 192-240, Nebraska: University of Nebraska Press.

23. Kepner, C. H. \& Tregoe, B. B. (1965) The rational manager. New York: McGraw-Hill.

24. Kozielecki, J. (1972) A Model for Diagnostic Problem Solving. Acta Psychologica, 36: 370-380.

25. Kuhn, T. S. (1980) The structure of scientific revolutions. Chicago: U. Chicago Press.

26. Mackie, J. L. (1974) The cement of the universe: A study of causation. London: Oxford University Press.

27. Mankelwicz, J. M. \& Kitahara, R. (2008) Propositions to Guide Evidence-Based Decision-Making. Journal of Business and Economics Research. 6(10): 41-55.

28. March, J. G. The business firm as a political coalition. The Journal of Politics, 1962, 662-678.

29. March, J. G. \& Simon, H. A. (1958) Organizations. New York: John Wiley

30. Mitchell, R. K., Agle, B. R. \& Wood, D. J. (1997) Toward a Theory of Stakeholder Salience: Defining the Principle of Who and What really counts. Academy of Management Review, 22: 853-886.

31. Morgenstern, I. (1960) The dimensional structure of time. New York: Philosophical Library

32. Nozick, R. 1993) The nature of rationality. Princeton: Princeton University Press.

33. Ornstein, R. E. (1969) On the experience of time. Baltimore: Penguin Books.

34. Poincare, H. (2004) Science and method. New York: Barnes \& Noble.

35. Rest, J. R. (1986) Moral development: Advances in research and theory. New York: Praeger.

36. Reynolds, S. J. (2006) Moral Awareness and Ethical Predispositions: Investigating the Role of Individual Differences in the Recognition of Moral Issues. Journal of Applied Psychology, 91(1):233-243.

37. Segev, E. (1977) Triggering the Decisionmaking Process. Management Decision, 14(5):229-238.

38. Simon, H. A. (1945) Administrative Behavior. $3^{\text {rd }}$ Ed. New York: Free Press.

39. Simon, H. A. (1983) Reason in human affairs. Stanford, Cal.: Stanford University Press.

40. Simon, H. A. (1986) Rationality in Psychology and Economics. Journal of Business, 59: 209-224.

41. Simon, H. A. (1995) Rationality in Political Behavior. Political Psychology, 16: 45-63.

42. Thompson, J. D. (1967) Organizations in action. New York: McGraw-Hill.

43. Zwiebach, B. (2009) A first course in string theory. Cambridge: Cambridge University Press. 